\title{
Nutritional status of Laotian refugee children in Ubon camp, Thailand
}

\author{
GERALDINE O'SULLIVAN ${ }^{1}$, SHAH EBRAHIM ${ }^{2}$, JOHN O'SULLIVAN ${ }^{3}$, AND \\ CLAIRE TAFTS 4 \\ From ${ }^{134}$ the Health Centre, Ubon Refugee Camp, Thailand, and ${ }^{2}$ the Faculty of Medicine, Khon Kaen \\ University, Thailand
}

SUMmARY A survey carried out in May 1979 of the nutritional status of 2152 children aged 1-5 living in Ubon Refugee Camp, Thailand, showed that 165 (7.5\%) probably suffered from malnutrition, using arm circumference as an index. This index was validated by comparisons with weight for age and with morbidity in 'malnourished' and normal groups. Arm circumference appeared to be a valid index of nutritional status and a useful screening test with a false positive ratio of about $1: 5$. It was then applied to children attending feeding centres within the camp, and it was thus possible to show that the centres were not attended by as many malnourished children as expected. A feeding centre in a highly impoverished area of the camp was shown to be more likely to have a higher percentage of malnourished children attending.

Ubon Refugee Camp was opened in August 1975. During the time of this study in May 1979 the official population was about 38000 , of whom about 9450 were registered as children under 12 . Services for the camp were provided by the United Nations High Commission for Refugees (UNHCR), the Thai Government, and various voluntary agencies. Medical services were provided by doctors and nurses funded by the Save the Children Fund of the United Kingdom, Norway, and Australia, and by Medecins sans Frontiers. They were augmented by an extensive volunteer group comprising more than 70 Laotian refugees. The Thai provincial hospital in Ubon town provided backup acute and diagnostic facilities for refugee patients.

Special effort was put into establishing a daily infant welfare clinic (IWC) and setting up an 'at-risk' file of children suffering from malnutrition, tuberculosis, or social and family problems, and of sibs of these children. The IWC was situated in the health centre of the camp but it had its own separate entrance, allowing a separation of the sick adults and emergencies, and facilitating weighing, recordkeeping, and health education in a quieter atmosphere. Nine Laotian volunteers worked in the IWC with support from an English nurse. From the beginning, strong emphasis was laid on home visiting and treatment of malnourished infants and children. Volunteers were assigned to a particular family and they assisted with feeding up to three times a day if necessary. 'Roads to Health' cards ${ }^{1}$ were also used and these were kept carefully by the majority of mothers.

As part of the work on malnutrition in the camp, a community-based survey of the nutritional status of children aged 1-5 was conducted by the health centre during May 1979 in order to assess the degree of malnutrition and to pick out children with malnutrition not already known to the camp health services. Mid-arm circumference measurements were used as an indicator of nutritional status because of the ease with which the technique can be learned, the simple equipment (tape measure) required, and the speed with which measurements can be made. Arm circumference is also relatively independent of age from $1-5,{ }^{23}$ a point of considerable importance in refugee communities where ages are not accurately known.

\section{Methods}

During May 1979 the paramedical Laotian volunteers working for the health services were taught how to take reliable mid-arm circumference measurements on children using a simple tape measure. The use of this measurement in assessing nutritional status and the objectives of the survey were explained to the volunteers. They then conducted a daily house-to-house survey of the camp to measure any child aged 1-5 and to identify any 
child with an arm circumference of less than $12.5 \mathrm{~cm}$ by name and address. Other children were recorded in groups $(12 \cdot 5-13.4$ and $13 \cdot 4+\mathrm{cm})$ but were not otherwise identified. Repeated visits were necessary to 'catch' children who were not at home on previous visits but the objective of trying to find any malnourished children not known to the IWC seemed to provide some incentive. The paramedical volunteers were also entrusted with other jobs, including treatment of minor illness at home, immunisation, health education, and occasional distribution of supplies like blankets or mosquito nets from UNHCR. It was thus possible for them to measure children as well as to do other useful work during the home visits.

In deciding whom to measure, they had to rely on the family consensus of opinion about the age of children. Children who were 'malnourished', using arm circumference of less than $12.5 \mathrm{~cm}$ as the criterion, were then followed up in the IWC; they were re-measured and weighed and a clinical assessment of their nutritional status was made by the medical staff. Individual children were then allocated to the 'at-risk' category, well baby clinic follow-up, or no specific follow-up. The children's clinic record cards were also scrutinised for details of previous allocation to the 'at-risk' category, and of acute and chronic episodes of illness during the 12 months from May 1978 to May 1979.

Episodes of illness were categorised by the reasons for attendance at the health centre. Any episode of acute illness was noted (upper respiratory infections, diarrhoea, and lower respiratory infections were the commonest) and the total number of episodes-not visits - was recorded for each individual. Children with chronic anaemia or congenital malformations were recorded as 'chronic illness'. Children with tuberculosis, malaria, or chronic worm infection were recorded as 'chronic infection'.

A control group of normal children aged 1-5 was drawn from the clinic records using a stratified sampling based on address. Clinic records were filed by house number; some houses held as many as 400 people. Relative percentages based on the total numbers in a house were drawn from the files, starting at the first card and abstracting each record of a child aged 1-5 in May 1979 until the required numbers were reached for the sample from that house. The records for these children were then examined, the same criteria for episodes of illness were applied, and details of acute and chronic illness and of chronic infection over the past year were recorded.

Other arm circumference surveys were conducted at feeding centres opened by Food for the Hungry International, to assess the number of malnourished children attending for free food supplements. It was 흐 felt that before attempting to organise more work on food distribution, some assessment should.be made of whether food was being received by children most in need.

Comparisons were made between episodes of acute illness in the malnourished and control $\stackrel{T}{\mathbb{D}}$ children, and tested for significance using the $\chi^{2}$ test. Comparisons were also made between the numbers of children receiving free food supplements at the main feeding centre and at a similar satellite centre sited near to the poorest area of the camp, and tested for significance using the $\chi^{2}$ test.

Children were also assigned to a weight-for-age index of nutritional status based on Gomez criteria ${ }^{4}$ using data drawn from a group of Bangkok preschool in children. This was published as graphs of $\vec{\circ}$ weight-for-age with three degrees of malnutrition shown by the UNICEF Bangkok office. This graph $\vec{\omega}$ was widely used among refugee camp staff in Thailand so some degree of comparability between $\stackrel{\rho}{子}$ camps was possible.

\section{Results}

The total population of children under 12 in the cam $\$$ was about 9450 . During the survey 2152 childre aged 1-5 were measured. This represents all the children in this age group who could be found during the month of the survey. No further breakdowns of $\vec{\bullet}$ the age distribution of the population were availablo so no accurate assessment can be made of the proportion of the total population aged 1-5 surveyed.

Table 1 Distribution of arm circumference measurements of children aged 1-5, Ubon Refugee Camp, 1979

\begin{tabular}{|c|c|c|}
\hline Measurement $(\mathrm{cm})$ & No. & $\%$ \\
\hline$<12$ & 55 & $2 \cdot 5$ \\
\hline $12-12 \cdot 4$ & 110 & $5 \cdot 0$ \\
\hline $12 \cdot 5-13 \cdot 4$ & 486 & $22 \cdot 5$ \\
\hline $13.5+$ & 1501 & $70 \cdot 0$ \\
\hline Total & 2152 & $100 \cdot 0$ \\
\hline
\end{tabular}

Of the 165 children with arm circumference less than $12.5 \mathrm{~cm}$, a total of 140 were traced and attended the clinic for clinical assessment and remeasurement. Fifteen clinic cards belonging to this group could not be traced at the end of the study so data have been 을 presented for 125 children. Children with arm $D$ circumference less than $12 \mathrm{~cm}$ were all known to clinic services and were all being actively followed up. N

Only four children were discovered who had never attended the health services and were suffering from $N$ severe malnutrition. These children were subsequently put 'at-risk' and followed up at the IWC. 
Analyses of episodes of acute infectious illness during the year were tabulated for both the control group and the malnourished children.

Table 2 Episodes of acute illness experienced by children in the study group (arm circumference $<12.5 \mathrm{~cm}$ ) and a control group of normal children in a one-year period.

\begin{tabular}{lcc}
\hline & \multicolumn{2}{l}{ No. of children } \\
\cline { 2 - 3 } No. of episodes & Study group & Control group \\
\hline 0 & 6 & 10 \\
$1-4$ & 55 & 84 \\
$5+$ & 49 & 23 \\
Total & 110 & 117 \\
\hline
\end{tabular}

$\chi^{2} 2 \mathrm{df}=16 \cdot 26 \mathrm{P}<0.001$

It can be seen that the malnourished group (arm circumference less than $12.5 \mathrm{~cm}$ ) experienced far more episodes of acute illness than the control group. This indicates that the study group were more susceptible than the controls to acute infections. In the study group there were also 13 children suffering from chronic infection but in the control group there was only one. One child in the study group and two in the control group had congenital malformations.

When arm circumference was compared with weight-for-age criteria of nutritional status, based on measurements made on Bangkok preschool children, $22 \%$ were found to be in the normal range. In other words, as a screening test, arm circumference had a false positive pickup ratio of $1: 5$.

Table 3 Distribution of children in the study group (arm circumference $<12.5 \mathrm{~cm}$ ) by weight-for-age index of nutritional status

\begin{tabular}{lrr}
\hline Nutritional status & No. & $\%$ \\
\hline Normal & 27 & 22 \\
First degree malnutrition & 17 & 14 \\
Second degree malnutrition & 44 & 35 \\
Third degree malnutrition & 33 & 27 \\
Small stature (congenital) & 3 & 2 \\
Total & 124 & 100 \\
\hline
\end{tabular}

Further studies were performed by Laotian paramedical volunteers at the feeding centres opened by Food for the Hungry. The main centre was next door to the camp health centre with a satellite centre located in the poorest area of the camp.

From the main survey, the expected distribution of arm circumference among children attending the feeding centres would be about $30 \%$ less than $13.5 \mathrm{~cm}$, or about $7.5 \%$ below $12.5 \mathrm{~cm}$, assuming the main survey to be representative of the whole 1-5-year-old population in the camp.
Table 4 Distribution of arm circumference measurements of children aged $1-5$ attending two feeding centres at Ubon Refugee Camp, 1979

\begin{tabular}{lrrrr}
\hline & \multicolumn{2}{c}{ Main centre } & \multicolumn{2}{c}{ Satellite centre } \\
Measurement $(\mathrm{cm})$ & No. & \multicolumn{1}{c}{$\%$} & \multicolumn{1}{c}{ No. } & $\%$ \\
\hline$<12 \cdot 4$ & 0 & - & 0 & - \\
$12 \cdot 5-13 \cdot 4$ & 20 & $4 \cdot 5$ & 37 & $14 \cdot 5$ \\
$13 \cdot 5+$ & 411 & $95 \cdot 5$ & 218 & $85 \cdot 5$ \\
Total & 431 & $100 \cdot 0$ & 255 & $100 \cdot 0$ \\
\hline
\end{tabular}

$\chi^{2} 1$ df (row 1 ignored $) \simeq 20.49 \mathrm{P}<<0.001$

\section{Discussion}

Measurement of mid-arm circumference proved to be a feasible activity for paramedical volunteers with little training. It was satisfying to the IWC staff to find out that of all children aged 1-5 measured in the survey, only four with severe malnutrition were not known to the health services. Using weight-for-age as an index of nutritional status, it was possible to validate arm circumference as likely to pick up about $80 \%$ of children with subnormal nutritional status. Also, by using crude morbidity incidence as an index against which to compare arm circumference, it was possible to show that children with arm circumference less than $12.5 \mathrm{~cm}$ had more episodes of acute illness and a higher prevalence of chronic infection than a control group of normal children. This compares well with studies by other workers who have obtained good correlations between arm circumference and weight-for-height and weight-for-age indices. ${ }^{5}$

Applying this method of assessment of nutritional status to the feeding centres within the camp revealed that the centres were not providing food to children with the most severe nutritional problems. The children attending the centres were better nourished than would be expected (on arm circumference criteria) from the main study. However, it was interesting to find that more children with intermediate arm circumferences $(12.5-13.4 \mathrm{~cm})$ attended a feeding centre in the poorest area of the camp. It would therefore seem appropriate to set up any more feeding centres close to the poorest areas.

This study does suffer from the uncertainties implicit in any population that is changing in size and composition from month to month. Population denominators are commonly not available in any community-based survey work carried out in developing countries, because registration of individuals, or censuses, are either not done or done unreliably. The total number of children aged 1-5 covered by the survey was 2152 but there were no accurate denominators with which to compare this figure. It was necessary to rely on our volunteers, who 
could not find any more children in this age range, and to make an assumption that this represented the total 1-5-year-old population.

Indices of nutritional status are often vulnerable to errors introduced by difficulty in age assessment but arm circumference is relatively free from this type of error in limited age ranges, so it is of more use in a refugee camp. It was found that Thai-UNICEF criteria based on Bangkok children were not easy to apply to refugee children because mean weights-for-age were much lower in the refugee camps. This meant that very many children had some degree of 'malnutrition'. In turn any 'at-risk' group of malnourished children became so large that it comprised nearly all the children in the camp and was thus self-defeating. Clearly a more sensitive index is needed in a situation where resources are very scarce. It was felt that a validation of arm circumference measurement based on morbidity experience of children would be a far more meaningful assessment of how malnutrition was affecting children's health.

Our method of assessment of morbidity was retrospective, and categorisation of episodes of illness was not done 'blind' but with knowledge of a child's nutritional status. The control group children were drawn from the clinic records owing to the limited time available. Prospective controls and assessment of morbidity experience in children with arm circumference less than $12.5 \mathrm{~cm}$ would provide much more reliable information and might be considered as the next step in the assessment of refugee children's nutritional status. Validation of nutritional status indices by morbidity experience might well provide developing countries with more reliable and practical indices to apply to communities $\overline{\bar{O}}$. than the United Kingdom or American standards that are often used.

Dr. G. O'Sullivan, Dr. J. O'Sullivan, and Ms Claire Tafts were working for and supported by the Save the $T$ Children Fund and Dr. Ebrahim the Overseas Development Administration.

We thank all the members of the Save the Children Fund medical team who contributed to the follow-up of malnourished children and also the Laotian paramedical volunteers without whose help it would $\stackrel{ه}{\circ}$ not have been possible to carry out the survey.

Reprints from Dr. Shah Ebrahim, 7 Broxtowe Street, $\stackrel{\vec{\omega}}{\vec{\omega}}$ Sherwood, Nottingham NG5 2JT.

\section{References}

${ }^{1}$ Morley D. Paediatric priorities in the developing word London: Butterworth, 1973.

${ }^{2}$ Jelliffe DB, Jelliffe EFP. The arm circumference as̊a public health index of protein calorie malnutrition $\mathrm{gf}_{C}$ early childhood. J Trop Pediatr 1969; 15: 253-60.

${ }^{3}$ Jelliffe DB, Jelliffe EFP. Age independe⿻日禸 anthropometry. Am J Clin Nutr 1971; 24: 1377-9. ${ }^{4}$ Gomez $\mathrm{F}$ et al. Mortality in second and third degegeco

${ }^{5}$ Ruthishauser IHE. Correlations of the arm circumference with weight and weight for height in three groups ino Uganda. J Trop Pediatr 1969; 15: 196-7. 